\title{
Span of Attention across Stages of Intellectual Impairment: Does Affective Stimulation Matter?
}

\author{
Anwesha Chakrabarti, Mallika Banerjee \\ Department of Psychology, University of Calcutta, Kolkata, India \\ Email: tua.chk@gmail.com, mallib@hotmail.com
}

Received January $30^{\text {th }}, 2013$; revised February $26^{\text {th }}, 2013$; accepted March $23^{\text {rd }}, 2013$

\begin{abstract}
Copyright (c) 2013 Anwesha Chakrabarti, Mallika Banerjee. This is an open access article distributed under the Creative Commons Attribution License, which permits unrestricted use, distribution, and reproduction in any medium, provided the original work is properly cited.
\end{abstract}

\begin{abstract}
The present study explores how affectivity and abstraction value influences the span of attention of normal and retarded population. Five intellectual functioning groups were chosen, six in each $(\mathrm{N}=30)$, from both sexes, age of 11 - 23 (mean age 17.36) years from the urban hospitals and educational institutions. For standardization of stimulus materials and controlling of extraneous variables three preliminary experiments were done. A repeated measure experimental design was followed in the main study. Result shows attention span tends to decrease with an increment in abstraction level in the lower range of intellectual ladder. Affective loading in stimulus materials does not enhance the span of attention, per se it inhibits cognition. The result was interpreted in the light of behavioural observation during the experimental conditions as well as the obtained statistical output. Overall analysis revealed that the persons with moderate retardation scored better in attention span in comparison to mild retarded group where average group scored highest. So, the result of span of attention did not follow the ladder of intellectual impairment. The causal attribution on result was interpreted in terms of environmental distraction and the lack of basic cognitive need of the moderately retarded persons which inversely facilitated better attention span as their attention span remains unaffected by distraction. The result is helpful to design the learning materials for the specific intellectual group.
\end{abstract}

Keywords: Span of Attention; Intellectual Impairment; Concrete-Abstract Stimulus Dimension; Cognitive-Affective Stimulus Dimension

\section{Introduction}

Intelligence, as a subjective factor of cognitive functioning, must play an important role in attention. Earlier studies in the area of short term memory created somewhat confusing picture. Some research suggested that the performance of children with mental retardation was no different from that of non-disabled individuals. Many methodological limitations with this early memory research made interpretation very difficult (Drew et al., 1996). Some other group of studies has mentioned that mental retardation is characterized by low attentional capacity. Luria (1963) has mentioned that the defective orienting reaction of the retarded, which prevents efficient attention to novel stimuli, is responsible for their learning failures.

The early test developers assumed that there is a positive correlation between intelligence and the ability to maintain attention to a task (Crosby et al., 1968). Zeaman et al. (1963) have postulated that a low initial probability of attending to relevant dimensions of a stimulus display is responsible for impairment shown by retarded individuals in visual discrimination learning. But Crosby noted that the studies done by Zeaman have been limited to visual learning to moderately retarded children. Denny $(1964,1966)$ also attributed the impairment which persons with retardation show in learning to an attention deficit problem. A number of authors in past literature explain the short attention span of retarded individuals in a number of ways. Hutt and Gibby (1965) opined that attention deficit in retarded individuals is a result of persistent anxiety, where as Zigler (1966) has suggested that distractibility or outer directedness is the key factor for poor attention in this group. So, the past literature has noted that persons having mental retardation are characterized by low attention span, but there is poor literature which states how it is related to the progressive degree of impairment. One of the prime aims of the present study is to uncover how the different intellectual functioning levels respond in span of attention task.

As the early literature has suggested attention gets affected by the complex interplay among a number of subjective and objective factors. Nature of stimulus quality has been proved to be a significant determinant for attention. This nature of stimulus quality may be varied in a number of ways. For example, stimulus sets can be varied in terms of living or non-living objects, or human figures and animal figures. In the present study the nature of stimulus has been varied from two different perspectives: one is changing the abstraction level and other is changing the affective value in stimulus category.

Processing of concrete and abstract ideas was a keenly investigated area from 1970s with the emergence of dual coding hypothesis (Paivio, 1971). When concrete and abstract words are given, concrete words are better recalled, and in comparison to words pictures are reproduced easily (Schwanenflugel \& Stowe, 1989; Paivio, 1971, 1986; Richardson, 2003). Hinojosa et al. 
(2001) showed that Recognition Potential (RP) of concrete and abstract words that actually differ in their degree of imageability (ability to form image) and semantic processing areas in which the RP originates display a higher activation for concrete (more imageable) material compared with abstract words and pseudo words. In terms of concreteness effects in verbal memory, performance measure typically indicates that concrete words are easier than abstract words (Howe \& Hunter, 1985). Concreteness has been shown to influence the recall pattern of both young and old adults, although it is not always clear whether the magnitude of this effect is developmentally invariant (Craik et al.). This concrete-abstract stimulus processing is a very much relevant issue in intellectual deficiency. It hampers in their conceptualization of ideas as well as making relations between two or more concepts. Concrete materials are easier to process they are more sensual where as abstract stimuli are more conceptual, having less physical referents. Concretizing the stimulus material it may help them in learning and understanding the external world. The present study intends to see how concretization influences perception in intellectually impaired group.

Literature suggests there emotion plays a great role in regulation of attention. It serves an environmental cue to prioritize cognition (Lazzarus, 1991; Simon, 1967). According to Dolan (2002), one of the emerging fields of psychological research is to know how emotion interacts with and influences other domains of cognition, memory and reasoning. Waring (2010) noted that many earlier studies demonstrated that emotionally charged items are more likely to attract attention than are emotionally neutral stimulus. Evidence from a variety of sources shows when both emotional and neutral items complete for processing resources; emotion is able to bias the competition (Desimore et al., 1995). According to Anderson (2005) emotion modulates the attentional blink and impairs concurrent task performance in divided attention paradigms (Talmi et al., 2007) and slows down font-colour naming in the Stroop task (Hadley et al., 2006). Anthony (2004) viewed the role of affection on attention from a phenomenological perspective and described how several level of affective force are related to mode of attentiveness. According to cognitive tuning model positive affect promotes cognition as it generates relational, heuristic and intuitive processing style. In contrast negative affect inhibits cognition by giving rise item specific, systematic or reflective processing (Strack \& Duetch, 2004).

Although the role of affection on cognition is well researched area, but how it is further connected to intellectual impairment is a rarely studied area. The present experiment aims at finding out how different levels of intellectual impairment perform in attentive task when the stimulus has affective loading. So, another way of varying the nature of stimulus, in this study, is to vary the affective value within stimulus category. In this study "Affective value" is defined as the amount of emotive components embedded in a particular form of stimulus. When feelings and emotions are attached with stimulus category it is termed as affectively loaded stimulus and the stimulus without the desired level of emotive value is termed as cognitively loaded stimulus.

Following Darwinian Theory of natural selection, it may be said that emotion accompanies an aroused physiological state which gives rise to express the felt emotion by bodily gestures, facial expressions along with different verbal and nonverbal cues. Expression of emotions has survival value (Darwin, 1872) that serves a particular form of communication between ones inner subjective state with the outside objective world.

Goleman's (1995) theory of emotional intelligence showed the importance of understanding other's emotions in social and interpersonal context. As a number of social skills it is another deficit area for persons with mental retardation. The emotionspecificity hypothesis states that mental retardation is associated with deficits in decoding facially expressed emotions that cannot be fully accounted for by mental age (Rojahn et al., 1995). However not a sufficient number of research was found to reveal this area much clearly. The present study intends to see the impact of affective value on attention task in different intelligence level.

In the present study, attempt has been made to study the cognitive ability (through attention span), of the individuals having below average IQ score, in cognitive and affective loaded stimuli by varying levels of abstraction of the same stimulus. Among these two categories of stimuli, both of the stimulus categories requires cognitive processing, but the affective stimuli consists significantly higher affective value and thus labeled as so. It is to be explored by this study to find out with a given level of impairment, how much abstraction level could be afforded in cognitive and affective dimension.

So, the objectives of the present study are to see whether 1) Span of attention differs across various levels of intellectual functioning; 2) Span of attention differs with the variation of levels of abstraction; 3) Span of attention differs with the affective quality of stimulus.

\section{Method}

\section{Participants}

Thirty (six in each group) $11-23$ years (mean 17.5 years) old individuals having different range of intellectual functioning are taken from various special educational institutions and hospitals. They have been categorized according to their intellectual status as measured by Binet Kamat Intelligence Test in the following groups: Average (IQ range 90 - 110), Dull normal (IQ range 80 - 89), Border line (IQ range 70 - 79), Mildly retarded (IQ range 50 - 69), and Moderately retarded (IQ range 35 - 49). Only individuals having the mother tongue of either Hindi or Bengali and having the ability to read words either in Bengali or in English were taken for the study. All the individuals had the history of schooling for at least two years. Individuals having any associated disability except mental retardation and having any history of major psychological illness were excluded from the study.

\section{Materials and Design}

For the main study six stimulus cards were used; three for cognitive dimension and three for affective dimension varying the levels of abstraction in each category. They have been labeled as cognitively loaded and affectively loaded stimulus category respectively (Figure 1).

\section{Stimulus Card Description}

In each condition, 8 stimuli were presented simultaneously against a background of $24 \times 15$ inch white chart paper. The inter-stimulus distance was kept constant by placing all the stimuli equidistantly. The relative positions of each 8 stimuli (for each cognitive and affective dimension) were kept constant. 


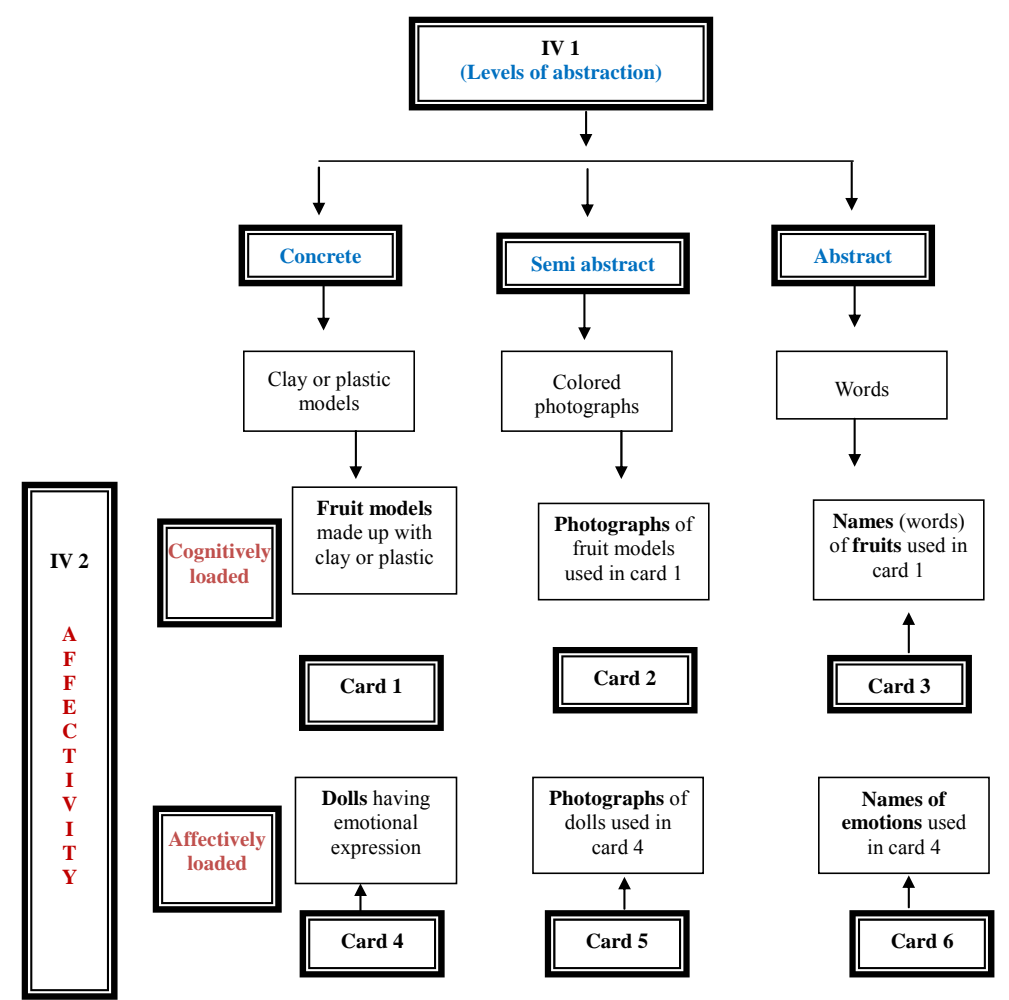

Figure 1.

Description of six cards used.

For the purpose of maximizing experimental control, 3 preliminary studies have been done regarding categorization of cognitive and affective loaded stimulus category, standardization of emotional stimulus, checking the possible order effect.

\section{Preliminary Study 1}

What should be called an emotional stimulus? Can anything be termed as a neutral stimulus? Any stimulus has its existence in its perceiver's experience. Despite of all the objectivity perception is to some extent subjective. Thus emotionality within the stimulus material can only be evaluated by the perceivers. The terms "emotional stimulus" can appropriately exist when the stimulus arise the feeling of emotion in a generalized population. A "non emotional" or "neutral stimulus" is when despite of its subjective association with personal emotion a large population of observers interpret it as "not having emotional tone within the stimulus" or "emotion is not induced within the stimulus". Hence, the objective of conducting this pilot study was categorization of all the stimuli according to the affectivity associated with the stimulus so that the terms like "cognitively loaded" and "affectively loaded" stimulus category can safely be used. Here, the aim was to determine quantitatively how much emotional value is embedded in each of the stimulus categories. On the basis of this result it is to be seen whether we can label the two sets of stimuli as "cognitively loaded" and "affectively loaded" stimulus category or not.

\section{Method}

\section{Participants}

15 subjects of 17 - 30 years age range, both male and female,

were having normal intellectual capacity without any record of psychological disorder.

\section{Procedure}

Each of the 16 stimulus items ( 8 fruit models and 8 dolls) were presented randomly one by one. Subjects were asked to see them carefully and judge how much emotional state is revealed by the object. The subjects were further cautioned not to judge the objects by their personal feeling attached with them, rather to judge how much emotional value is there in the object, whatever the particular emotion is. Whatever the emotion they felt they were asked to judge the objects in $0-5$ point rating scale and to rate the potential emotionality embedded in the objects, where 0 means no emotionality is embedded, and 5 means maximum emotionality is embedded and $1-4$ points were to be assigned in the scale for gradually increasing the degree of emotional values in an equal interval.

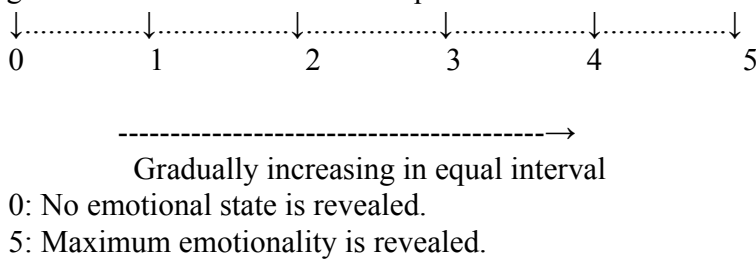

\section{Result and Discussion}

All the fruit models together received $7 \%$ emotional value as judged by 15 subjects, whereas, the dolls having different emotional expressions received $81.4 \%$ emotional value. The maximum emotional value of $12 \%$ was received by the fruit "man- 
go" among all the fruits and a minimum value of $69.4 \%$ was received by the doll labeled as "relaxed" among all the dolls.

So, it may be said that the dolls models can be labeled as "affectively loaded" stimulus category because it got significantly much high emotional value than that of the fruits models. Even, the maximum emotional value of fruits got $12 \%$ which is significantly lower than the minimum emotional value (69.4\%) received by dolls in one item.

\section{Conclusion}

On the basis of the above-mentioned judgment given by 15 subjects, it may be concluded that the fruits models can be labeled as "cognitively loaded stimulus" and the dolls having different facial features can be labeled as "affectively loaded" stimulus category having the consideration that cognition and affection are present in all perception, but in varying degree.

\section{Preliminary Study 2}

\section{Standardization of Emotional Stimulus}

Perception and recognition of emotion through facial and gestural expression was one of the main topics of investigation for many years to the researchers. Emotion by its character is being expressed through bodily gestures especially through face. This process has great adaptive value because of the fact that the generated emotion needs to be communicated to other members of society. Perceivers play a great role in this process to understand the expressed emotion. Recognition and understanding of the perceived emotion is not as simple as it seems to. Sometimes it involves a very much complicated process. Some other times subtlety within itself makes the process of understanding a little difficult. The concept of "mixed emotion" also makes it very much complicated. In spite of all the subjectivity recognition of expressed emotion has requires high objectivity in perception. Here, objectivity in this process means to label a same emotion by a wide group of perceivers. Here, the objective of the present study is to label each doll (used in the main study) by a particular emotional state by some groups of individual.

\section{Participants}

Depending on the final population (individuals with intellectual impairment) and the nature of stimulus materials (dolls having emotional expression) three groups of participants were chosen for the standardization of the expressed emotions. Ten children (of age-range 5 - 12 years), eleven psychologists and thirty one students of psychology were taken for this study.

As the main study is to be done among the intellectually impaired groups (marked by low mental age), the perception of emotion by another group having low mental age (due to chronological age) has been taken. So, the judgment regarding the expressed emotion by the children group was important and also got maximum priority while summarizing the data.

Judgments of psychologists about the expressed emotions revealed by the stimulus set were important, because by profession psychologists deal with peoples' emotion, perceptions, and expressions etc. So they are master in the task of interpreting others' facial expressions objectively.

Students of psychology were taken because of the fact that they are being trained to read others' emotions. So their judg- ments were important.

\section{Materials}

Only the 8 concrete models of dolls (prepared for the main study) were being used here for each subject.

\section{Procedure}

The eight doll figures were presented randomly one by one to all the three groups of subjects. Each individual was instructed to observe the doll figure very keenly and to label the expressed emotion by his own judgment and language. Here the opinion was open ended. The subjects were free to give any kind of answer coming in his/her mind. After collecting the data for each doll they were grouped or clustered in few categories. The answers which were semantically similar were regarded as same. For each doll the frequency of each answer was counted. The maximally agreed upon answer was finally taken to coin the doll with the particular emotion.

\section{Result and Discussion}

While summarizing the data, the synonymous words have been treated as the same. In this process, the mode values were calculated and used for the labeling of emotion (Table 1). So, a range of opinion has been considered as correct and same for a particular emotional expression. This method has been followed according to Izard's Differential Emotion Theory (1971). Following are the percentage of agreement in any emotion by all the groups.

\section{Preliminary Study 3}

\section{Checking the Possible Order Effect}

In a repeated measure design each individual is receiving a number of treatment conditions or levels of independent variables. As the different treatment levels are assigned to each individual there may be an order effect which contaminates the experimental findings. In order to eliminate the order effect statistically Latin square Design is used to compute ANOVA on small groups prior to the main study. So the aim is to see whether there is any order effect of stimulus card presentation.

Table 1.

Percentage of agreement of the most popular response.

\begin{tabular}{cccc}
\hline $\begin{array}{c}\text { Names of } \\
\text { emotions }\end{array}$ & Children & Psychologists & $\begin{array}{c}\text { Psychology } \\
\text { students }\end{array}$ \\
\hline Joyous & $100 \%$ & $100 \%$ & $96 \%$ \\
Surprised & $80 \%$ & $100 \%$ & $96 \%$ \\
Relaxed & $70 \%$ & $54 \%$ & $58 \%$ \\
Unhappy & $60 \%$ & $72 \%$ & $77 \%$ \\
Angry & $60 \%$ & $54 \%$ & $54 \%$ \\
Shocked & $60 \%$ & $40 \%$ & $51 \%$ \\
Naughty & $100 \%$ & $54 \%$ & $51 \%$ \\
Sad & $100 \%$ & $100 \%$ & $98 \%$ \\
\hline
\end{tabular}

Note: The percentage of frequency of response of each affectively loaded stimulus (dolls) used for labeling with the most popular response $(\mathrm{N}=52)$. 


\section{Participants}

Two intellectually impaired groups (mildly retarded intellectual functioning and border line intellectual functioning) were taken having 3 individuals in each group. The characteristics of this sample involve all the characteristics of the sample for the main study.

\section{Materials}

All the stimulus cards made for the main study are used here.

\section{Procedure}

Each card was presented for 30 seconds audio visually (as it is planned for the main study). A Latin square design was used to test the order effect due to stimulus presentation for both of the groups. The order of presentation of the same materials to different subjects, thus, has been distributed so that it cannot hamper the result.

\section{Result}

The data were calculated by Latin square ANOVA. The computation of Latin square design accounts the row and column variances also with the treatment effect. In the present pilot study as it is the prime aim to find out the order effect due to stimulus card presentation only the computation for the row variance was done. All the obtained $\mathrm{F}$ values were found to be not significant at .05 level (Table 2) which indicates for the two small groups the order effect, which is not treatment but affects the result, was not significant for order of stimulus cards presentation.

\section{Conclusion}

From the above study it may be concluded that the order effect is not significant here. Thus for the main study the order effect has not been considered.

\section{Procedure of the Main Study}

\section{Stimulus Presentation}

Based on the preliminary studies done prior to the experiment stimulus cards were presented. Each stimulus was presented audiovisually. But while visually all the stimuli were presented simultaneously, auditory labeling were made one by one. The visual part contained the independent variable and thus varied across conditions, while the auditory part remained the same for each stimulus in affective and cognitive dimension.

The auditory presentation was used as a controlling technique for a number of extraneous factors. Firstly, to overcome

Table 2.

F values for row variance (order of presentation) in two groups.

\begin{tabular}{ccc}
\hline Card & Subjects mild & Borderline \\
\hline Cognitive & 6.97 & 7.74 \\
Affective & 1.61 & 1.02 \\
\hline
\end{tabular}

Note: F values of row variance of possible order effect in a Latin square design in two intellectual functioning groups $(\mathrm{N}=3$ in each) in both cognitive and affectively loaded stimulus categories. the subjectivity in perception of the stimulus materials (both in case of fruits and emotions), verbal labeling was used. Secondly, to reduce the subjectivity in processing speed, audiovisual presentation was used. Thirdly, In other words to increase inter-subjectivity, verbal suggestion was used. Lastly, attempt has been made to draw attention by involving the subject's both sense organs (visual and auditory) towards a given stimulus in a given time.

\section{Sequence of Stimulus Card Presentation}

The abstract materials were presented at first which has the lesser probability to carry over imageries. In each condition cognitively loaded stimulus category is presented at first, followed by the affectively loaded stimulus category. It is because the fruits models are more familiar and easy to process for them.

The difficulty level in cognitively loaded stimulus category was low in the sense they are more concrete and easy to image than emotions. The less difficult and more familiar materials were presented at first to make the subject more comfortable and easy with the experimental conditions.

Each stimulus card was shown for 30 - 35 seconds and it was read out twice. The inter condition gap was kept 1 hour in between abstract, semiabstract and concrete level. Within this 1 hour the subjects were gone for different cognitive activities studying in class, or performing some kind of academic task.

Within each condition (abstract, semiabstract and concrete) two set of stimulus categories (cognitively loaded and affectively loaded) were presented. The gap between these two levels was 2 minutes. Usually all the experimental conditions were completed within a day.

\section{Data Collection}

For taking the attention span 30 individuals of different intellectual status were taken. The DV measure (recall) was taken immediately after the presentation of stimulus card. The subjects' were encouraged to recall maximally. Verbal support (feedback) was required for some people to make him or her easier with the experimental set up and overcome their shyness (if any). Some forms of these verbal feedback are "yes, right, and? What else? Say. You have said very well." Maximum effort has been given, form the part of the experimenter to elicit the total response from the subject. No time limit was maintained strictly. But after a given amount of response from the subject, about 2 minutes pause was tolerated to give him or her chance to make any more response. It was ensured that the subject does not remember anything else. Subjects' responses were noted down and behavioural observations were made.

\section{Scoring}

Scoring was done taking into account the disability of the subjects. For this reason a relative lenient stance was taken to score the responses. If the subject gives the right name of the fruits and emotions, it is considered correct (in any language among Hindi, English and Bengali).If the subject gives wrong answer, i.e., the names of other fruits not used here, further probing is made to ensure the subject's imagery regarding the given fruit (that $\mathrm{s} /$ he has said) was not there in the stimulus card. If it matches with an existing one, the answer is considered as correct. If the subject gives wrong answer, but cannot describe 
it in any way which matches with the existing stimuli, the answer is considered as wrong and therefore gets no mark. Same rule was applicable for all emotional stimuli also.

\section{Result}

The data obtained from the different groups of subjects were arranged properly with respect to each of the variables considered in the present study.

The data were then analyzed statistically in accordance with the objectives of the present study. At first, the means and standard deviations of the groups on the scores of different variables are computed (Table 3). Their intergroup and intra group comparisons were attainted with independent and repeated measures used in suitable nonparametric statistical tests.

\section{Intergroup Comparisons}

For the purpose of the analysis of data, intergroup comparesons were made with respect to cognitively loaded and affectively loaded stimuli separately. Here, for testing the significance of differences among the five groups classified on the basis of the levels of intellectual functioning, the nonparametric statistical test, that is Kruskal-Wallis One-Way Analysis of Variarce by Ranks was used (Siegel \& Castellan, 1988).

This test was applied separately for comparing the groups in respect of each of the three levels of abstraction, namely concrete (CC), semiabstract (SA) and abstract (ABS). These group comparisons were attainted separately with each of the stimulus category namely, cognitively loaded and affectively loaded. The statistical vales of Kruskal-Wallis test were designated as

\section{$K W$ values (Table 4)}

\section{Intragroup Comparisons}

This part of the analysis was based on repeated measures obtained from three levels of abstraction by the same subjects belonging to a particular group. For the purpose of intra group comparisons among the three levels of abstraction the nonparametric statistical test that is the Friedman Two-Way Analysis of Variance by Ranks was used. This test was used for the significance of differences among the three levels of abstraction separately in each of the five groups. The value obtained from the Friedman test was designated as Fr (Table 5).

\section{Multiple Comparisons}

The present multiple comparisons follows a procedure which is considered to be an extension of the Friedman Two-Way Analysis of Variance by Ranks. This procedure is based on critical $\mathrm{Z}$ values for particular number of multiple comparisons. The present analysis involved 3 multiple comparisons and accordingly the $Z$ value was determined. Then the critical value was worked out taking the $Z$ value in to account and following the procedure as stated in the extended Friedman test. The significance of difference between any two levels of abstraction was checked against the obtained critical value (Siegel \& Castellan, 1988)

It might be stated here that, multiple comparisons between the groups would be attainted only when the value of Fr indicating a significant difference among the 3 levels of abstraction for a particular group. The obtained results showed that the $\mathrm{Fr}$

Table 3.

Mean and $S D$ of span of attention score of five groups.

\begin{tabular}{|c|c|c|c|c|c|}
\hline \multirow{2}{*}{ Int. Grp } & \multirow{2}{*}{ Levels of abstraction } & \multicolumn{3}{|c|}{$M$} & \multirow{2}{*}{$\begin{array}{l}S D \\
\text { Aff. }\end{array}$} \\
\hline & & Cog. & Aff. & Cog. & \\
\hline \multirow{3}{*}{ Average } & Concrete & 7.5000 & 7.3333 & .83666 & 1.21106 \\
\hline & Semiabstract & 7.3333 & 7.0000 & .81650 & 1.26491 \\
\hline & Abstract & 6.5000 & 5.6667 & 1.76068 & 1.63299 \\
\hline \multirow{3}{*}{ Dull normal } & Concrete & 7.0000 & 5.5000 & .63246 & 1.37840 \\
\hline & Semiabstract & 6.8333 & 5.0000 & .75277 & 1.26491 \\
\hline & Abstract & 5.6667 & 4.3333 & 1.50555 & 1.50555 \\
\hline \multirow{3}{*}{ Border line } & Concrete & 6.5000 & 5.8333 & 1.51658 & 1.16905 \\
\hline & Semiabstract & 5.8333 & 5.5000 & 1.47196 & 1.64317 \\
\hline & Abstract & 5.0000 & 4.5000 & 1.67332 & 1.37840 \\
\hline \multirow{3}{*}{ Mildly retarded } & Concrete & 5.5000 & 4.1667 & .83666 & .75277 \\
\hline & Semiabstract & 4.8333 & 3.5000 & .75277 & .83666 \\
\hline & Abstract & 4.1667 & 2.3333 & .98319 & 1.36626 \\
\hline \multirow{3}{*}{ Moderately retarded } & Concrete & 5.8333 & 5.8333 & 1.16905 & .75277 \\
\hline & Semiabstract & 5.5000 & 5.5000 & 1.22474 & .89443 \\
\hline & Abstract & 4.6667 & 4.6667 & .81650 & 1.26491 \\
\hline
\end{tabular}

Note: The result shows the mean and standard deviation values of span of attention for five intellectual functioning groups $(\mathrm{N}=30)$ in both cognitively loaded and affectively loaded stimulus categories in each of the three levels of abstraction. Aff. = Affectively loaded category; Cog. = Cognitively loaded category; Int. Grp. = Intellectual functioning group. 
Table 4.

$K W$ values among the five groups in each of the three levels of abstraction.

\begin{tabular}{ccc}
\hline & $\begin{array}{c}\text { Cognitively loaded } \\
\text { stimulus category }\end{array}$ & $\begin{array}{c}\text { Affectively loaded } \\
\text { stimulus category }\end{array}$ \\
\hline Concrete & 7.096 & $15.067^{* *}$ \\
Semiabstract & $14.263^{* *}$ & $11.222^{*}$ \\
Abstract & $12.071^{*}$ & $14.417^{* *}$ \\
\hline
\end{tabular}

Note: Kruskal Wallis values for the significance of difference among the five groups $(\mathrm{N}=30)$ in each of the three levels of abstraction in both the cognitively loaded and affectively loaded category. ${ }^{*} p<.05 ;{ }^{* *} p<.01$.

Table 5.

Fr values among the three levels of abstraction in each of the five groups.

\begin{tabular}{ccc}
\hline $\begin{array}{c}\text { Intellectual } \\
\text { functioning group }\end{array}$ & $\begin{array}{c}\text { Cognitively loaded } \\
\text { stimulus category }\end{array}$ & $\begin{array}{c}\text { Affectively loaded } \\
\text { stimulus category }\end{array}$ \\
\hline Moderately retarded & 4.765 & $9.000^{*}$ \\
Mildly retarded & $10.000^{* *}$ & 4.900 \\
Borderline & $10.300^{* *}$ & .597 \\
Dull normal & 4.849 & 5.158 \\
Average & 5.600 & 3.265 \\
\hline
\end{tabular}

Note: Freidman values significance of mean difference among three levels of abstraction in each of the five intellectual functioning group $(\mathrm{N}=30)$ in both cognitively loaded and affectively loaded stimulus category. ${ }^{*} p<.05 ;{ }^{* *} p<.01$

values were significant in border line and mildly retarded intellectual functioning group. The obtained $\mathrm{Fr}$ values were not found to be significant in case of moderately retarded, dull normal and average intellectual functioning group of the cognitively loaded stimulus category. For this, the present multiple comparisons were attainted with respect to mildly retarded (Group 2) and borderline intellectual functioning (Group 3) for cognitively loaded stimulus category (Table 6) and it is attained to moderately retarded group (Group 1) for affectively loaded stimulus category (Table 7).

\section{Comparisons between Cognitively and Affectively Loaded Stimuli}

An attempt was made in the present study to test the significance of difference between cognitively and affectively loaded stimulus categories with respect to certain variables. This comparison was based on repeated measures since the same subjects belonging to a particular group were exposed to both categories of stimulus. For the purpose of comparison between these two stimulus categories the nonparametric statistical test that is The Wilcoxon Signed Ranks Test was used (Siegel \& Castellan, 1988).

The statistic to be obtained from the Wilcoxon test was designated as $T+$. The differences between the two stimuli categories were tested in each level of abstraction for the different groups separately (Table 8). The obtained results are given in the following tables.
Table 6.

Post hoc analysis between levels of abstraction for cognitively loaded stimulus category.

\begin{tabular}{ccccccc}
\hline Group & \multicolumn{3}{c}{ Mildly retarded } & \multicolumn{3}{c}{$\begin{array}{c}\text { Borderline intellectual } \\
\text { functioning }\end{array}$} \\
\hline $\begin{array}{c}\text { Levels of } \\
\text { abstraction }\end{array}$ & $\begin{array}{c}\text { ABS \& } \\
\text { SA }\end{array}$ & $\begin{array}{c}\text { ABS \& } \\
\text { CC }\end{array}$ & $\begin{array}{c}\text { SA \& } \\
\text { CC }\end{array}$ & $\begin{array}{c}\text { ABS \& } \\
\text { SA }\end{array}$ & $\begin{array}{c}\text { ABS \& } \\
\text { CC }\end{array}$ & $\begin{array}{c}\text { SA \& } \\
\text { CC }\end{array}$ \\
\hline Average ranks & $\begin{array}{c}1.17 \& \\
2.00\end{array}$ & $\begin{array}{c}2.83 \& \\
1.17\end{array}$ & $\begin{array}{c}2.00 \& \\
2.83\end{array}$ & $\begin{array}{c}1.08 \& \\
2.17\end{array}$ & $\begin{array}{c}1.08 \& \\
2.75\end{array}$ & $\begin{array}{c}2.17 \& \\
2.75\end{array}$ \\
Critical values & 1.39 & 1.39 & 1.39 & 1.39 & 1.39 & 1.39 \\
$\begin{array}{c}\text { Differences of } \\
\text { average ranks }\end{array}$ & .83 & $1.66^{* *}$ & .83 & 1.09 & $1.67^{* *}$ & .58 \\
\hline
\end{tabular}

Note: Post hoc analysis showing the mean difference between pairs of abstraction levels in both mildly retarded $(\mathrm{N}=6)$ and borderline intellectual functioning $(\mathrm{N}=$ 6) groups. $\mathrm{ABS}=\mathrm{Abstract}$ Level; $\mathrm{SA}=$ Semiabstract Level; $\mathrm{CC}=$ Concrete Level. ${ }^{*} p<.05 ;{ }^{* *} p<.01$

Table 7.

Post hoc analysis among levels of abstraction for affectively loaded stimulus category.

\begin{tabular}{cccc}
\hline Group & \multicolumn{3}{c}{ Moderately retarded } \\
\hline Levels of abstraction & ABS \& SA & ABS \& CC & SA \& CC \\
Average ranks & $1.25 \& 2.00$ & $1.25 \& 2.75$ & $2.00 \& 2.75$ \\
Critical values & 1.39 & 1.39 & 1.39 \\
$\begin{array}{c}\text { Differences of } \\
\text { average ranks }\end{array}$ & .75 & $1.50^{*}$ & .75 \\
\hline
\end{tabular}

Note: Post hoc analysis showing the mean difference between pairs of abstraction levels in moderately retarded group $(\mathrm{N}=6) . \mathrm{ABS}=$ Abstract Level; $\mathrm{SA}=\mathrm{Semi}-$ abstract Level; $\mathrm{CC}=$ Concrete Level. ${ }^{*} p<.05 ;{ }^{* *} p<.01$.

Table 8.

$T+$ values between cognitively loaded and affectively loaded stimulus categories in each of the three levels of abstraction.

\begin{tabular}{cccc}
\hline $\begin{array}{c}\text { Intellectual } \\
\text { functioning group }\end{array}$ & Abstract & Semiabstract & Concrete \\
\hline $\begin{array}{c}\text { Moderately } \\
\text { retarded }\end{array}$ & 12.00 & 8.00 & 1.5 \\
Mildly retarded & $15.00^{* *}$ & $15.00^{* *}$ & $15.00^{* *}$ \\
Borderline & 3.00 & 3.00 & $16.00^{* *}$ \\
Dull normal & $15.00^{* *}$ & $21.00^{* *}$ & $15.00^{* *}$ \\
Average & 8.00 & 4.50 & 2.00 \\
\hline
\end{tabular}

Note: Values of Willcoxon signed rank test shows the significance of mean difference between cognitively loaded and affectively loaded conditions in each level of abstraction for each intellectual functioning group $(\mathrm{N}=30) .{ }^{* *} p<.01$.

\section{Discussion}

Among the different groups in all levels of abstractions of both cognitively loaded (Figure 2) and affectively loaded stimulus categories (Figure 3), the highest score is achieved by average intellectual functioning group, followed by dull normal, borderline, moderately retarded and mildly retarded intellectually functioning groups. Starting from mild intellectual functioning, as the intellectual status increases, the span of attention also increases gradually. 


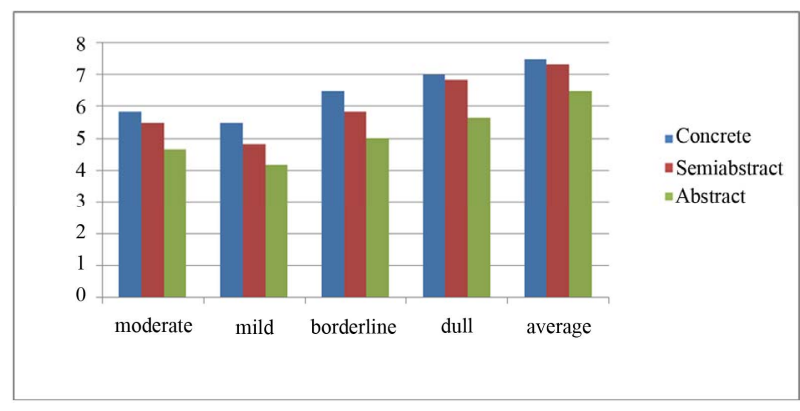

Figure 2.

Mean of attention span among the five intelligence groups in three abstraction levels in cognitively loaded stimulus category.

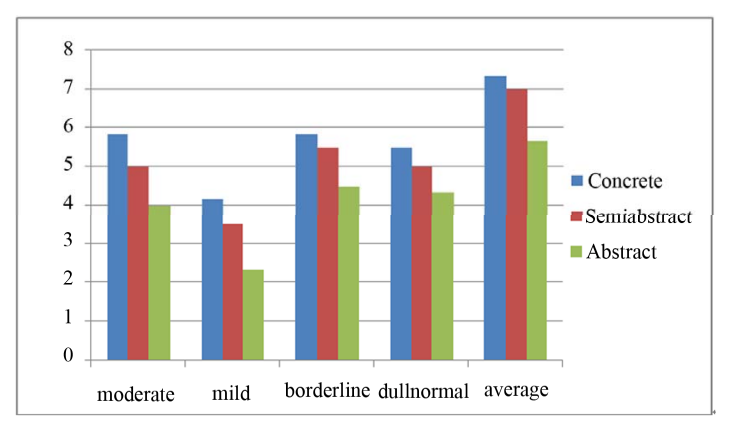

Figure 3.

Mean of attention span among the five intelligence groups in three abstraction levels in cognitively loaded stimulus category.

Here the striking result is the moderately retarded group performs better than mildly retarded intellectual functioning group in case of measuring attention span.

By the behavioural observation from the part of the experimenter, it can be interpreted as the rote memory, which does not demand semantic understanding, works well in moderately retarded level of intellectual functioning and there was lesser degree of distraction by the environmental stimuli in them, as the interest to explore environment is less in moderately retarded intellectual functioning. This is so because the demand to discover the surroundings is not developed in this group. The semantic network is not properly formed. So higher level cognitive tasking is not met by them, only the rote memory is activated and along with it lesser level of distraction made the attention span better than mildly retarded intellectual functioning. This study was not intended to measure long term memory. Other past literatures have noted that the inefficient rehearsal strategies that interfere with long term memory (Brooks \& McCauley, 1984) and inability to transfer learned materials results in deficits in learning and cognitive systems in mental retardation. The earlier researches in the area of short term memory drew a somewhat confusing picture. Some research suggested that the performance of children with mental retardation was no different from that of non disabled individuals. Many methodological limitations with this early memory research made interpretation very difficult (Drew et al., 1996). The present study has answered the question in a way that in moderately retarded intellectual functioning, attention span or short term memory span comes better than that of mildly retarded intellectual functioning group for lower distraction and better rote memory from the par. Here, with the relatively higher intellectual functioning the need for exploring the environment is high. In mildly re- tarded intellectual functioning group the attention span was so less because they have developed the interest to know the surrounding world. In spite of providing the same set of instruction their behaviour and activity were interfered by distraction. The behavioural observation says they were unable to focus their attention. In higher intellectual functioning group the need to know the environment is higher but cognitive capacity also develops better. So, although they get distracted minimally by the surroundings more efficient cognitive strategies prevent their forgetting and facilitate recall of items that was previously attended.

It is seen that for all the given groups of intellectual functioning the mean of attention span is highest in concrete level, intermediate in semiabstract level and least in abstract level (Figures 2 and 3). So, more the stimulus is concrete, more is the probability here to be attended well. This finding is consistent with that of Craik \& Massani (1969) who concluded with the finding that concreteness has been shown to influence the recall pattern of both young and old adults, although it is not always clear whether the magnitude of this effect is developmentally invariant. The differences among the means in all the three levels of abstraction are significant at .05 level for some groups (i.e. mildly retarded group and borderline intellectual functioning group in case of cognitively loaded stimulus category (Table 6) and moderately retarded intellectual functioning group in case of affectively loaded stimulus category (Table 7). Although with the increment in concretization level the attention span increases gradually, the difference between concrete and abstract is consistently yielding better cognitive output and is statistically significant. Statistical significance denotes the difference between concrete and abstract stimulus category much high and statistically significant than that of between concrete and semiabstract or between semiabstract and abstract stimulus. So, if the abstract mode seems to be difficult in intellectually impaired group then the instructor may go for concrete or semiabstract mode of instruction. If the concrete mode helps their learning, then the next step is to go for the semiabstract mode (as the difference between concrete and semiabstract level is not statistically significant). After that instructor may move to abstract set of learning material (as the difference between abstract and semiabstract level is not statistically significant). Thus semiabstract stimulus may be used as learning material when the person has difficulty in acquiring abstract form of stimulus in intellectually impaired group. Also as the transition between concrete and abstract is much harder, so a semiabstract level may often be introduced in between the two extreme to smooth the ladder of transition. The result also shows that this mean difference among the levels of abstraction is only significant in groups having intellectual impairment but not in average or dull normal intellectual functioning group in the given level of difficulty. It means that the extent to which the difference in abstraction level in stimulus sensitizes the cognition of persons having intellectual difficulty, it does not do so for the two higher intellectual groups for the given difficulty level. Thus concrete and semi abstract levels of stimulus or learning materials may facilitate learning and cognition.

Comparing between the cognitively loaded and affectively loaded stimulus category, it is seen that in all abstraction level the former yields greater attention span although it is statistically significant at .05 level in the middle range of the continuum of intellectual functioning. This result is consistent in concrete (Figure 4), semiabstract (Figure 5) and abstract (Figure 6) 


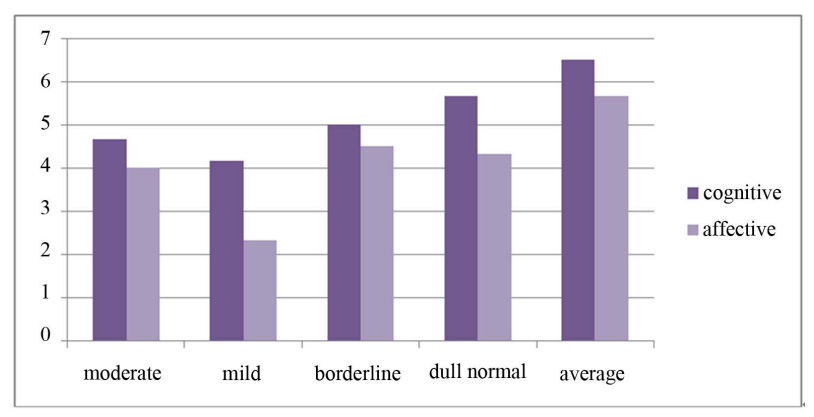

Figure 4.

Mean of attention span of five different intelligence groups in cognitively \& affectively loaded stimuli in case of abstract stimuli.

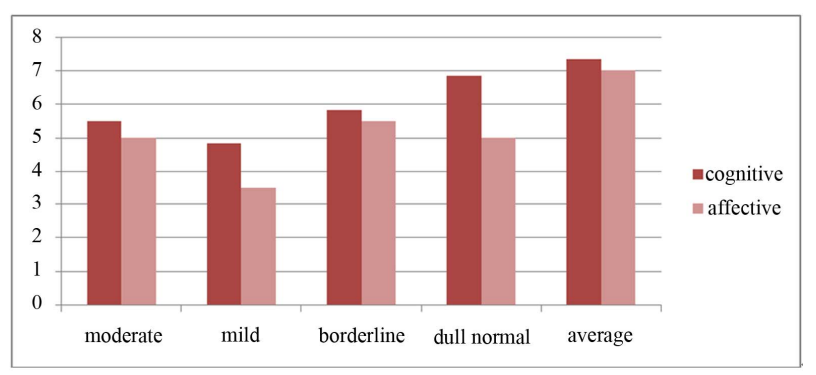

Figure 5.

Mean of attention span of five different intelligence groups in cognitively \& affectively loaded stimuli in case of semiabstract stimuli.

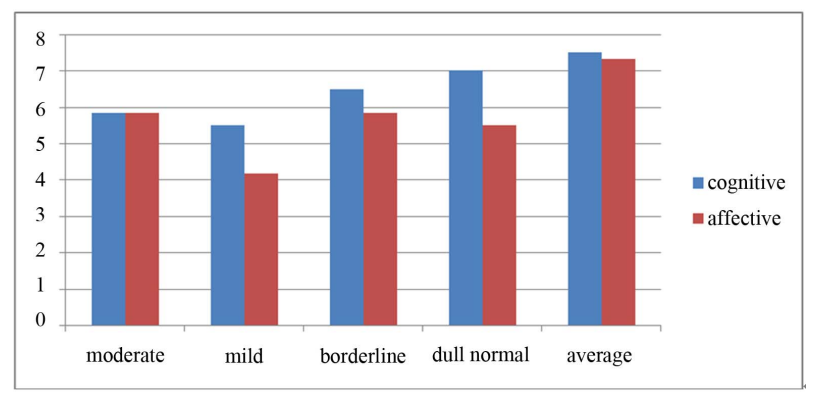

Figure 6.

Mean of attention span of five different intelligence groups in cognitively \& affectively loaded stimuli in case of concrete stimuli.

stimulus category. The two extreme in this continuum is less affected by the affective stimulation and this is because of probably two different reasons.

For average intellectual functioning group the difference is not significant because the difficulty level in two different stimulus categories was too easy for them and both have been processed more or less similarly, although their performance is slight better in cognitively loaded stimulus category. In average intellectual functioning group this makes no statistically significant difference because the average groups can overcome the emotional clouding better by utilising different strategies by a well formed executive functioning. According to Anderson (2005) emotion modulates the attentional blink and impairs concurrent task performance in divided attention paradigms (Talmi et al., 2007) and slows down font-colour naming in the stroop task (Mackay et al., 2006). In this study the attention span is interfered with the affection embedded in stimulus category.

For moderately retarded intellectual functioning group, it is noted earlier also that the rote memory is unaffected by the nature of stimulus. So, be it affective or cognitive, they processed more or less similarly for a brief period of time as the semantic processing is weak in them.

But in the middle range of intellectual functioning the performance is better in cognitive loaded stimulus category may be because of the fact that the affective stimulation generates affective processing and it interferes with the cognitive processing which hinders cognitive performance or it is because of the fact that the stimulus used in cognitive category is more familiar to them. So, affective stimulation does not facilitate cognitive performance. Many investigators have reported that people with mental retardation have problem on emotion recognition tasks (Moore et al., 2001). The present study corresponds with this fact.

Overall analysis shows that the nature of stimulus contributes much in cognitive functioning i.e. span of attention. Affective component in stimulus material does not facilitate cognitive processing, per se; it hinders the scores on attention span. Cognitively loaded stimulus seemed to be beneficial for the scores of attention span. The span of attention scores increase gradually as the intellectual status increases (from mild to average intellectual functioning). Moderately retarded group performed better than mildly retarded and for them the span of attention score does not vary much with the variation in stimulus category probably because of their problem in semantic processing for the variation. For all the groups concrete stimuli yield better attention span score but in case of intellectually impaired group this concretization in stimulus material is significantly fruitful. The result may be helpful to understand how the intellectual ladder is affected by changing in stimulus category. Moreover, the result gives an indication to design the study material for specific group of intellectual functioning.

\section{Conclusion}

The present study shows how variation in nature of stimulus affects the span of attention on various levels of intellectual functioning. It arrives at the following conclusions: 1) Along with the increment in levels of abstraction the attention span tends to decrease in all level of intellectual functioning groups ranging from moderately retarded intellectual functioning to average intellectual functioning group; 2) Significant differences are seen in between concrete and abstract level in the intellectually impaired groups, but no significant difference is found in attention score between concrete and semiabstract or between abstract and semiabstract; 3) Affective loading in stimulus category does not enhance the span of attention, per se, it inhibits the cognitive performance in all intellectual functioning groups; 4) The differences in performance in cognitive loaded and affective loaded stimulus categories are significant statistically in mild retardation, borderline and dull normal intellectual functioning groups, i.e., the middle range of the continuum; 5) The attention span of the moderately retarded intellectual functioning group is not affected much by the nature of stimulus category, probably because of better rote memory which is unaffected by distraction. The results may help to design the teaching tools and instruction mode for different intellectual functioning groups, so that it can facilitate learning maximally. The result is further helpful to see how the different intellectual functioning groups react differently in same kind of stimulus sets. So, while making the learning materials for specific groups, 
the present finding would be helpful. Furthermore, the result of the following study may initiate a number of different researches in the area of rote memory and affective stimulation across the different intellectual functioning groups.

\section{Acknowledgements}

AC thanks to Indian Council of Medical Research for the financial assistance. Sri Debabrata Biswas for academic guidance. Sri Sumon Mukherjee for valuable suggestion.

\section{REFERENCES}

Anderson, A. K. (2005). Affective influences on the attentional dynamics supporting awareness. Journal of Experimental Psychology: General, 134, 258-281. doi:10.1037/0096-3445.134.2.258

Anthony, J. S. (2004). Affection and attention: On the phenomenology of becoming aware. Continental Philosophy Review, 37, 21-43. doi:10.1023/B:MAWO.0000049298.44397.be

Brooks, P. H., \& McCauley, C. (1984). Cognitive research in mental retardation. American Journal of Mental Deficiency, 88, 479-486.

Craik, F. I., \& Masani, P. A. (1969). Age and intelligence differences in coding and retrieval of word lists. British Journal of Psychology, 60, 315-319. doi:10.1111/j.2044-8295.1969.tb01202.x

Crosby, K. G., \& Blatt, B. (1968). Attention and mental retardation. Journal of Education, 150, 67-81.

Darwin, C. (1872). On the expression of emotions in men and animals. London: John Murray. doi:10.1037/10001-000

Denny, M. R. (1964). Learning and performance. In H. A. Stevens, \& R. Heber (Eds.), Mental retardation: A review of research (pp. 100-142). Chicago: University of Chicago Press.

Denny, M. R. (1966). A theoretical analysis and its application to training the retarded. In N. R. Ellis (Ed.), International review of research in mental retardation (pp. 1-27). New York: Academic Press. doi:10.1016/S0074-7750(08)60201-3

Desimone, R., \& Duncan, J. (1995). Neural mechanisms of selective visual attention. Annual Review of Neuroscience, 18, 193-222. doi:10.1146/annurev.ne.18.030195.001205

Drew, C. J., Jardman, M., \& Logan, D. R. (1996). Mental retardation. A life cycle approach (6th ed.). London: Prentice Hall.

Drew, C. J., Hardman, M. L., \& Hart, A. W. (1996). Designing and conducting research in education and social science. Needham Heights, MA: Allyn \& Bacon.

Dolan, R. J. (2002). Emotion, cognition, and behavior. Review Neuroscience and Psychology, 298, 1191-1194.

Goleman, D. P. (1995). Emotional intelligence: Why it can matter more than IQ for character, health and lifelong achievement. New York: Bantam Books.

Hadley, C. B., \& Mackay, D. G. (2006). Does emotion help or hinder immediate memory? Arousal versus priority-binding mechanisms. Journal of Experimental Psychology Learning, Memory, Cognition, 32, 79-88. doi: $10.1037 / 0278-7393.32 .1 .79$
Hinojosa, J. A., Martín-Loeches, M., Fernández-Frías, C., \& Rubia, F. J. (2001). Functional differences in the semantic processing of concrete and abstract words. Neuropsychologia, 39, 1086-1096. doi:10.1016/S0028-3932(01)00033-1

Howe, M. L., \& Hunter, M. A. (1985). Adult age differences in storage-retrieval processes: A stages-of-learning analysis of developmental interactions in concreteness effects. Canadian Journal of Psychology, 39, 130-150. doi:10.1037/h0080119

Hutt, M. L., \& Gibby, R. G. (1965). The mentally retarded child (2nd ed.). Boston: Allyn \& Bacon.

Lazarus, R. S. (1991). Cognition and motivation in emotion. American Psychologist, 46, 352-367. doi:10.1037/0003-066X.46.4.352

Luria, A. R. (1963). The mentally retarded child. Oxford: Pergamon.

Moore, D. G. (2001). Reassessing emotion recognition performance in people with mental retardation: A review. American Journal on Mental Retardation, 106, 481-502. doi:10.1352/0895-8017(2001)106<0481:RERPIP >2.0.CO;2

Paivio, A. (1971). Imagery and verbal processes. New York: Holt, Rinehart, and Winston.

Paivio, A. (1986). Mental representations: A dual coding approach. New York: Oxford University Press.

Richardson, J. (2003). Dual coding versus relational processing in memory for concrete and abstract words. European Journal of Cognitive psychology, 15, 481-509. doi:10.1080/09541440244000256

Rojahn, J., Rabold, D. E., \& Schneider, F. (1995). Emotion specificity in mental retardation. American Journal on Mental Retardation, 99, 477-486.

Siegel, S., \& Castellan, N. J. (1988). Nonparametric statistics for the behavioral sciences. New York: McGraw-Hill.

Simon, H. A. (1967). Motivational and emotional controls of cognition. Psychological Review, 74, 29-39. doi:10.1037/h0024127

Schwanenflugel, P. J., \& Stowe, R. W. (1989). Context availability and the processing of abstract and concrete words in sentences. Reading Research Quarterly, 24, 114-126. doi:10.2307/748013

Strack, F., \& Deutsch, R. (2004). Reflective and impulsive determinants of social behavior. Personality and Social Psychology Review, 8, 220-247. doi:10.1207/s15327957pspr0803_1

Talmi, D., Anderson, A. K., Riggs, L., Caplan, J. B., \& Moscovitch M. (2007). Immediate memory consequences of the effect of emotion on attention to pictures. Learning and Memory, 15, 172-182. doi:10.1101/1m.722908

Waring, J. D., Payne, J. D., \& Kensinger, E. A. (2010). Impact of individual differences upon emotion induced memory trade-offs. Cognition \& Emotion, 24, 150-167. doi:10.1080/02699930802618918

Zeaman, D., \& House, B. J. (1963). The role of attention in retardate discrimination learning. In N. R. Ellis (Ed.), Handbook of mental deficiency (pp. 159-223). New York: McGraw-Hill.

Zigler, E. (1966). Personality structure in the retardate. In N. R. Ellis (Ed.), International review of research in mental retardation (pp. 77-108). New York: Academic Press. 